\title{
Understanding provider and parent experiences in caring for hospitalized young children: Summary findings from a formative study in Kenya
}

Breakthrough RESEARCH

Follow this and additional works at: https://knowledgecommons.popcouncil.org/departments_sbsr-rh How does access to this work benefit you? Let us know!

\section{Recommended Citation}

Breakthrough RESEARCH. 2020. "Understanding provider and parent experiences in caring for hospitalized young children: Summary findings from a formative study in Kenya," Programmatic Research Brief. Washington, DC: Population Council. 


\section{Understanding Provider and Parent Experiences in Caring for Hospitalized Young Children: Summary findings from a formative study in Kenya}

Understanding the health care experiences of young children (0-24 months) is critical to promoting positive health and developmental outcomes, yet few efforts have defined or measured the experience of facility-based care of this age group in low- and middle-income country settings. Although young children are unable to voice their own experiences, we can study their experiences by collecting responses from parents of hospitalized newborns and young children (0-24 months). It is also critical to understand the role of health providers, including their communication and behaviors with parents and families caring for hospitalized young children. A formative study was conducted under the Breakthrough RESEARCH project by the Population Council to understand the manifestation of mistreatment of newborns, infants, and young children (0-24 months) and co-design (with families and providers) a set of interventions that promote a positive experience of care. This brief summarizes those findings.

\section{Methods}

The study was conducted in five hospitals in Kenya: Pumwani Maternity Hospital, Mama Lucy Kibaki Hospital, and St. Mary's Hospital in Nairobi County; and Bungoma Referral Hospital and Webuye County Hospital in Bungoma County. In-depth interviews (IDIs) were conducted with policymakers, health providers, and parents of hospitalized

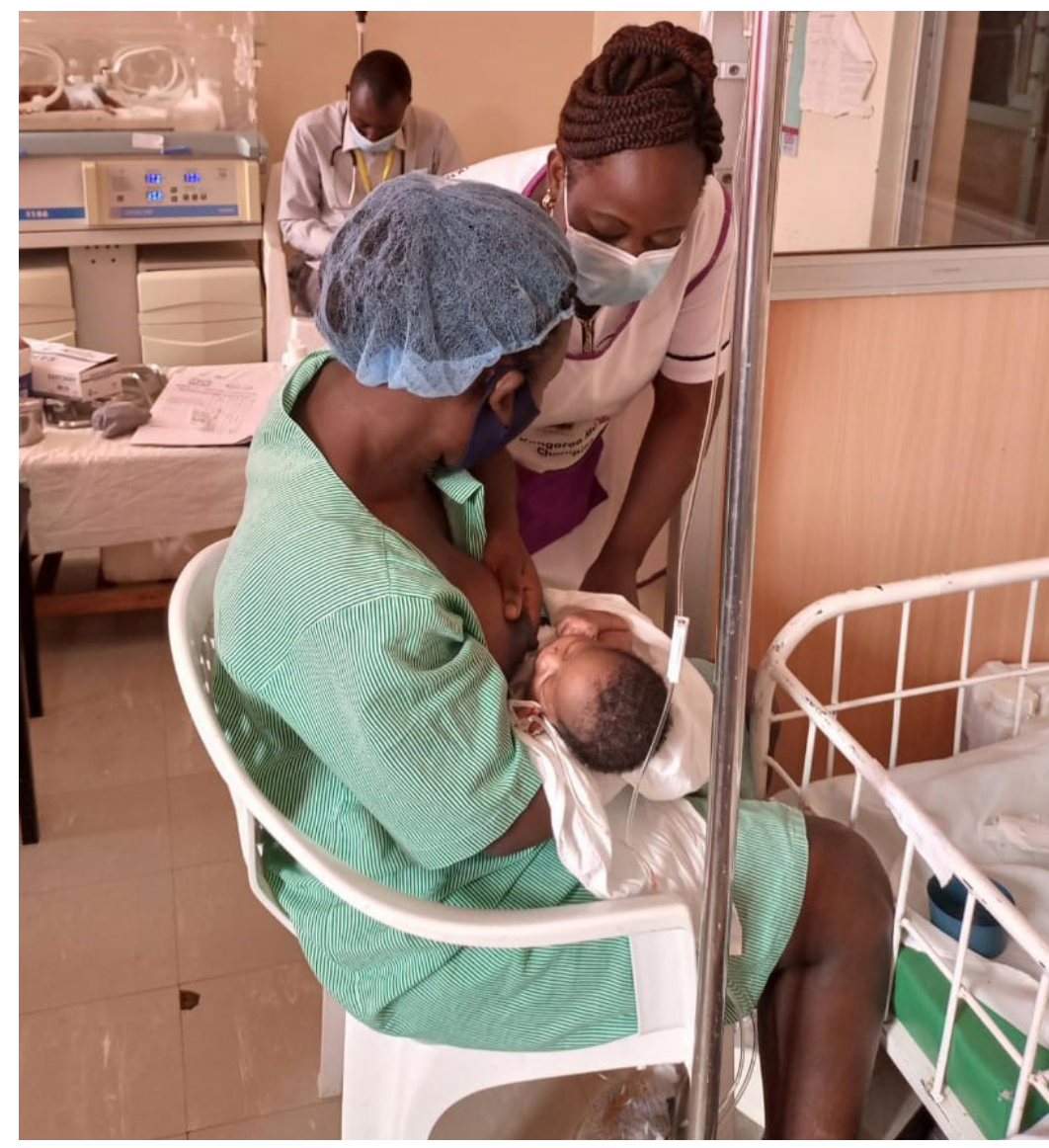

young children, and focus group discussions (FGDs) were held with mothers and fathers of hospitalized young children. Ethnographic observations were conducted at each hospital to understand organizational culture, service flow, and client management, and to determine provider practice norms (see Table 1 on next page for summary of study methods). Qualitative data was audio-recorded, transcribed verbatim, and translated into English. A thematic framework was developed, and data were analyzed using NVivo 12 software comparing age groups of children (0-59 days and 60 days -24 months) across study sites.

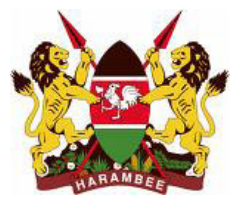


TABLE 1 STUDY METHODS AND PARTICIPANTS

\begin{tabular}{|c|c|c|c|}
\hline \multirow{2}{*}{$\begin{array}{l}\text { Study methods: data } \\
\text { collection activity }\end{array}$} & \multicolumn{3}{|c|}{ Number of interviews } \\
\hline & Nairobi & Bungoma & Total \\
\hline $\begin{array}{l}\text { IDIs with policymakers in child } \\
\text { health }\end{array}$ & 2 & 1 & 3 \\
\hline $\begin{array}{l}\text { IDIs with health providers in } \\
\text { postnatal, newborn, pediatric } \\
\text { units }\end{array}$ & 18 & 14 & 32 \\
\hline $\begin{array}{l}\text { Joint IDIs with both parents } \\
\text { of hospitalized children 0-24 } \\
\text { months }\end{array}$ & 11 & 12 & 23 \\
\hline $\begin{array}{l}\text { IDIs with single parents of } \\
\text { hospitalized children 0-24 } \\
\text { months }\end{array}$ & 1 & 1 & 2 \\
\hline $\begin{array}{l}\text { FGDs with fathers of } \\
\text { newborns/young children } \\
0-24 \text { months }\end{array}$ & 2 & 2 & 4 \\
\hline $\begin{array}{l}\text { FGDs with mothers of } \\
\text { newborns/young children } \\
\text { 0-24 months }\end{array}$ & 5 & 3 & 8 \\
\hline $\begin{array}{l}\text { Ethnographic observations in } \\
\text { hospitals }\end{array}$ & 33 & 31 & 64 \\
\hline
\end{tabular}

\section{Findings}

We present findings using four main themes: 1) experience and occurrence of mistreatment of young children and their parents; 2) health system and provider drivers of mistreatment; 3) interpersonal communication between providers and parents/caregivers; and 4) family involvement.

\section{Mistreatment of young children and their parents}

We identified eight categories of mistreatment experienced by parents and their young children.

Failure to meet professional standards were reported by both parents and providers. Providers were observed improperly administering medication (i.e., wrong dose) or not observing infection prevention practices. For example, a baby developed a septic wound on his lower limb after an intravenous line was left in use for a prolonged amount of time.
It really astonishes me when it comes to medicine administration.... when I saw the medicine, I asked the nurse, 'is that medicine too much for the baby?' She said she had forgotten and reduced the dosage.

$-F G D$, women with young infant $0-59$ days

Hand washing, which is very necessary, sometimes it's compromised, after handling this baby you are supposed to wash your hands before you handle the next one to prevent cross infection from one baby to another baby. It is not observed most of the time.

-IDI, healthcare provider

Abandonment, neglect, and delay of services: Women reported experiencing unattended labor in the facility that led to birth complications in their newborn babies, such as birth asphyxia, resulting in longer hospital stays. For older children, there were numerous instances of providers failing to respond to parents' requests, such as re-inserting tubes resulting in missed medication or feeding.

At one point, my child removed the feeding tube, and when she [mother] went to seek help from the nurse, she was told to wait. We waited from nine at night up to five in the morning, the baby did not feed throughout that time.

-Joint IDI, couple with young child 60 days-24 months

An example of negligence includes not securing the cot sides properly resulting in babes falling from incubators and cots.

...We were in the [phototherapy] room the other day, ...even the nurse was in there too and there was a child who fell out of the photo bed and no one knew about it, so when we were in the process of feeding these babies there is just one of us who saw 'it' and said, is this pampers or what and when we looked at 'it'...we found a baby.

-FGD, women with young infant 0-59 days

Discrimination: Parents reported feeling discriminated against by providers based on their appearance, education level, and economic status. Women who gave birth at home or at other institutions described being treated differently or being blamed for poor neonatal outcomes. 


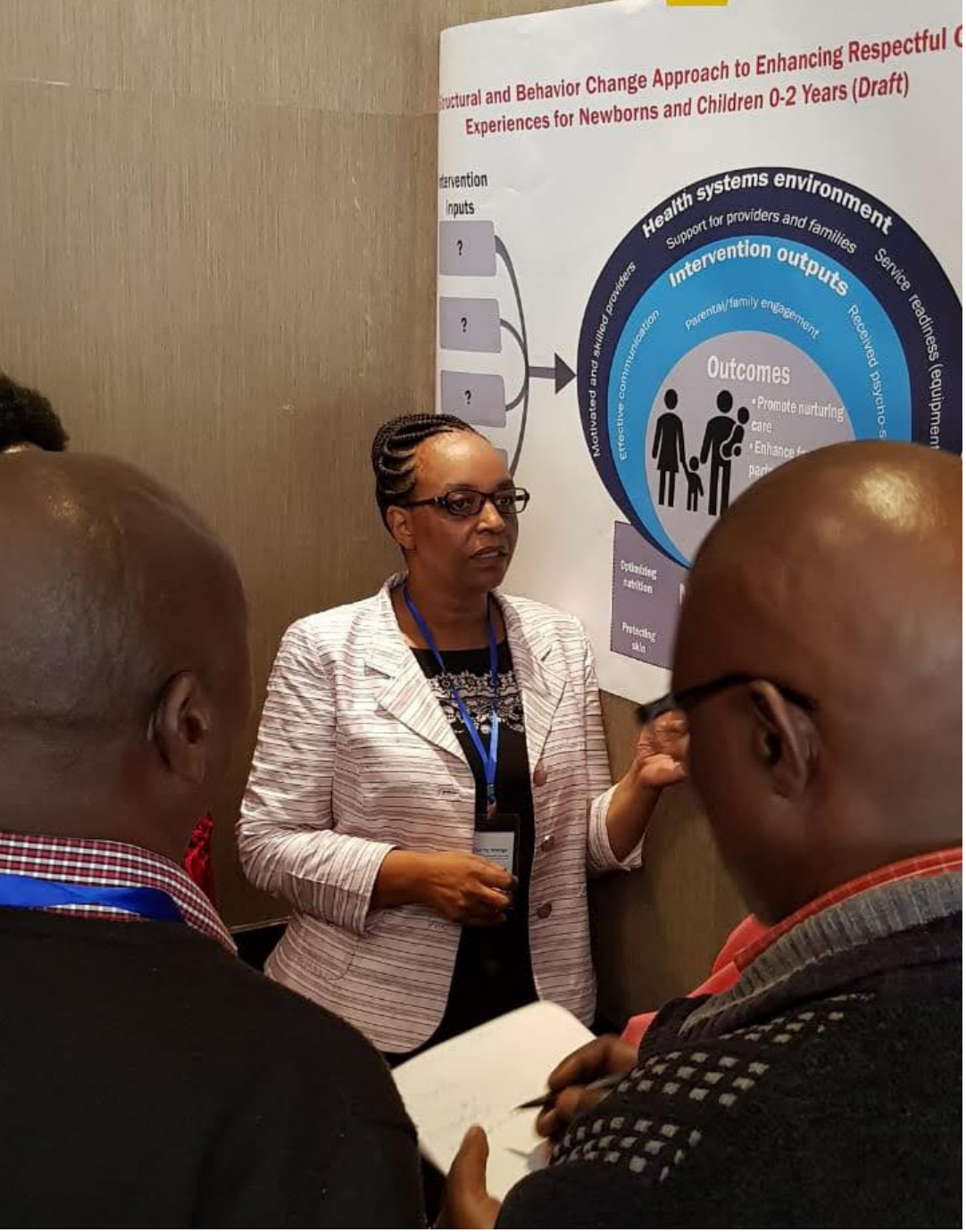

(C)Timothy Abuya/Population Council

The formative study findings were discussed with stakeholders to better understand the findings and inform the intervention design.

Some of the doctors check how the parents are dressed-when a parent comes with a child, he looks clean, he will attend.... If you look poor, and he treats you according to how you have come, he might not.

$-F G D$, fathers

Corruption and bribery were commonly experienced by parents. For instance, ambulance drivers demanded money to transport referred children. Complicated discharge processes made parents vulnerable to bribery to speed things up.

I can be told there are no drugs but another one will come and she/he will be given the same drug you were told were unavailable.... When you are told there are no drugs, they need you to bribe them.
Physical abuse: Poor positioning and handling while inserting a nasogastric tube, IV line, or frequent blood tests was observed.

While the doctor was putting the line and the baby was pierced severally. I tried to express the pain of the baby, but the doctor was like 'leave me to do my work' so he was harsh.... I felt so bad because the pricking was too much without success.

-FGD, women with young child 29 days -24 months

Verbal abuse was displayed by harsh tones and language. Parents were blamed for non-compliance to instructions and negative provider attitudes.

\section{She [nurse] lifted the skin off the baby's} chest like this and said, 'how does this one look, does she eat really, will this tiny baby really grow?'...and laughed. She humiliated me, some of the mothers looked at me laughed at me and some just kept quiet, it pissed me off till I cried.

-FGD, women with young infant 0-59 days

Unsupported care, bereavement, and posthumous care: Although facilities have social workers or counsellors, there were minimal efforts to provide emotional or counselling support for parents whose children had lengthy hospital stays or challenging diagnoses, or when an infant died.

Can you imagine the doctor came and told my wife that 'your baby was born...brain damaged!' She was in shock; she was just crying.... It affects us emotionally and psychologically because now when they tell you that your child is brain damaged, you see now they have discouraged you so much.

-FGD, fathers

When she came to ask, 'where is my baby?'

[she had been moved to the morgue] the nurse didn't tell her anything, she just left her standing there. That is when another nurse came and told her 'your baby didn't make it blah, blah,' just like that.

-Joint IDI, couple with young child 60 days -24 months 
Inappropriate feeding practice: There were several examples of parents trying to "forcefully" feed their babies for fear of being threatened with a longer hospital stay if the child did not thrive. Parents also feared being verbally abused by providers if the baby did not gain enough weight. The study team observed a nurse in one newborn unit strictly reminding mothers to feed their babies every three hours to shorten their hospital stay. The nurse would call out mothers from the postnatal ward and scold those who did not produce enough milk. This made mothers scared, and they were heard saying they can't wait to be discharged home with their babies as it was stressful for them. Another inappropriate feeding practice observed was feeding cups being shared without proper sterilization in the rush to feed multiple infants within allocated feeding times.

\section{Health system and provider drivers of mistreatment}

Facilities were found to be overcrowded and lacking adequate equipment and supplies (see Figure 1). Providers were reported as having inadequate skills and limited opportunities for training in neonatal care. Many providers feel overworked and underappreciated, lack confidence, and have limited competence in caring for hospitalized young children. Some of these provider drivers may deter parents from seeking care from what they experience as uncaring staff and may lead to unintended consequences of parents seeking care from unlicensed or unskilled providers.

\section{Interpersonal communication between providers and parents/caregivers}

Source of information: There is inadequate communication between health providers and parents, and parents end up receiving information from various sources, including doctors, nurses, laboratory staff, pharmacy staff, and support staff, as well as relatives. At times, the diverse sources provide varying information which can be confusing for parents.

\section{Nature of interaction and communication: Parents reported either a complete lack of communication from providers or inadequate or inconsistent explanations of their children's condition or treatment, e.g., blood samples were taken, or procedures conducted without explanation to the parent. Parents noted providers to be aloof or too busy to communicate with them. Fathers often felt ignored with no reliable access to information on their babies' condition while in hospital.}

\section{FIGURE 1 DRIVERS OF MISTREATMENT}

\begin{tabular}{|c|c|c|}
\hline $\begin{array}{l}\text { - Lack of qualification and } \\
\text { experience } \\
\text { - Insufficient communication and } \\
\text { emotional skills } \\
\text { - Heavy workload and inadequate } \\
\text { supervision } \\
\text { - Distractions and inattentiveness } \\
\text { (e.g., phone, TV) } \\
\text { - Poor communication between } \\
\text { doctors and nurses } \\
\text { - Poor or inconsistent remuneration }\end{array}$ & $\begin{array}{l}\text { - Lack of equipment, supplies, and } \\
\text { medicines (e.g., only an adult } \\
\text { breathing apparatus available for } \\
\text { neonatal resuscitation) } \\
\text { - Limited staff, poor workload } \\
\text { distribution } \\
\text { - Overcrowding and congestion } \\
\text { - Lack of accountability and } \\
\text { responsiveness-nowhere to } \\
\text { channel complaints } \\
\text { - Complex referral policies, lack of } \\
\text { guidelines and treatment protocols } \\
\text { for care of sick children }\end{array}$ & $\begin{array}{l}\text { - Provider/caregiver power } \\
\text { dynamics: parents fear providers } \\
\text { - Men are perceived not to play an } \\
\text { active role in caregiving, providers } \\
\text { do not encourage male presence } \\
\text { - Poor knowledge and illiteracy } \\
\text { among caregivers } \\
\text { - Negligence by caregivers and } \\
\text { misconceptions of certain } \\
\text { treatments can lead to non- } \\
\text { adherence } \\
\text { - Poor health literacy }\end{array}$ \\
\hline
\end{tabular}


I found them taking a blood sample from my

baby. I asked why because they took another one in the morning. They told me not to breastfeed; the baby is very sick. No one explained to me why. I felt annoyed till I cried.

-FGD, women with young infant 0-59 days

The frustration of having your wife there, the baby's condition also varies every day, like our baby's condition now at some point he dropped from 1.9 to 1.6, you know when you go there and ask your wife about such questions she will not know anything because she is very confused about the whole situation.... There should be a person there who can give you some information...like I remember one day and said, 'hi nurse, how is my baby doing,' and she said, 'what's his name, I am just getting in,' and that was it, until today.

- Joint IDI, couple with young infant $0-59$ days

Providers, however, reported not having enough time to adequately explain the condition and treatment progress for a hospitalized child. In most cases, parents were the ones who initiated interactions or communication with providers by asking questions.

Like you have $\mathbf{4 0}$ babies it is difficult to ask every mother how the baby is doing. So, we encourage them to ask questions...when the mothers come to feed, you inform them.... Please find out from me how much you are supposed to feed if you are not able to read whatever has been written in the feeding chart. Please ask so that I can be able to explain to you when feeding the babies.

-IDI, healthcare provider

\section{I think we are overworked...but I think with training in emotional management and communication skills, it will help. Some of us have had the opportunity to be trained on emotional management and communication skills so you're able to communicate in a good way, and actually if you talk to these mothers nicely it makes it easier for the mum, they even tell you the honest thing of what is happening.}

-IDI, healthcare provider
Adequacy of communication and the nature of interactions between providers and parents directly influenced the level of family engagement and confidence of parents to participate in care.

\section{Family involvement}

We identified four second-order themes that made family involvement challenging. They include limited visitation hours and feeding times. For example, the current protocols for visiting hours do not coincide with when working fathers are free, or set restrictive timing for feeding, every two to three hours only. Set feeding times for hospitalized newborns do not allow for a slow feeder or sleeping baby.

Those of us who have two children...we have
limited time to breastfeed.... You can find
one baby sleeping and as you struggle to wake
them up you are told time is over, so you find that
one child does not get milk well. So, you are asked
to leave and allocated the same time as someone
who has one child, and we have two.

$-F G D$, women with young infant $0-59$ days

Inadequate infrastructure: Parents of young children (59 days to 24 months) noted poor sleeping conditions in the wards, such as being forced to either share beds with their hospitalized child or sleep on the floor on cardboard, exposing them to infection and affecting their ability to look after their child and engage with the provider.

Limited capacity and skill set of providers: Providers were hesitant to involve parents due to lack of time and specific guidelines on how to involve parents, or to coach them on specific tasks such as giving medicines or naso-gastric tube feedings.

Because of the shortage, we teach the mothers and delegate to them. But mothers are not technical...we've had one or two incidents where the mother feeds and the baby aspirates after feeding.

-IDI, healthcare provider

In contrast, many parents want to be more involved in providing care for their hospitalized child through giving medicines, feeding, and handling their child with guidance from providers. Many fathers expressed interest in playing active roles in the treatment of their child. However, these fathers were often prevented from participation by facility 
visiting hours, physical space, sociocultural norms, and provider perceptions around male engagement in maternal, newborn, and child health.

Lack of financial assistance: Parents reported needing financial assistance due to the expense of unnecessary costly tests and treatment as well as food and other supplies such as diapers and toiletries while in the hospital. Some also requested more information and clarity on free services.

\section{I had to pay for an injection, so I wonder what the Linda Mama was for? I strug- gled until I had to sell my radio, I sold even another phone...in order to raise Ksh 5,000. And you can't buy the medicine outside the hospital, only at their pharmacy.}

-FGD, Fathers

\section{Conclusion}

These formative results demonstrate that there are numerous challenges and barriers experienced by hospitalized newborns and young children and their parents in a low resource setting. Approaches that build better communication, address the emotional needs of parents and providers, and provide supportive, enabling, and healthy environments will lead to more respectful care of hospitalized newborns and young children.

\section{Acknowledgments}

This programmatic research brief describes work led by the Population Council for the newborn activity in Kenya. We would like to thank Dr. Laura Oyiengo' (Head) and Dr. Carol Mwangi (Program Manager, Newborn and Nurturing Care Program) at the Division of Newborn and Child Health, Ministry of Health; Dr. Josephine Kibaru-Mbae (OGW, Director, Health Directorate), Dr Carol Ngunu (Head, Division of Communicable Diseases), and Ann Gathura (Focal Person Newborn and Child Health) at Nairobi Metropolitan Services; Dr Johnstone Akutu (Director of Health) in Bungoma County; Dr Felistus Makhoha (Pediatrician) at Bungoma County Referral Hospital; study participants (parents and providers); and Timothy Abuya, Charity Ndwiga, Chantalle Okondo, Pooja Sripad, and Dr. Charlotte Warren at the Population Council, whose support, leadership, and contributions have made this work possible.

\section{Suggested citation}

Breakthrough RESEARCH. 2020. "Understanding provider and parent experiences in caring for hospitalized young children:

Summary findings from a formative study in Kenya," Programmatic Research Brief. Washington, D.C.: Population Council.

Front cover photo credit: Catherine Asava, Webuye Subcounty Hospital

(C)2020 The Population Council. All rights reserved.

\section{Email}

\section{BreakthroughResearch@popcouncil.org}

\section{Breakthrough RESEARCH | Population Council}

4301 Connecticut Ave., NW, Suite 280 | Washington, DC 20008

+12022379400 | breakthroughactionandresearch.org

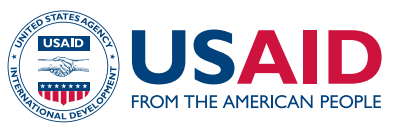

Breakthrough RESEARCH is made possible by the generous support of the American people through the United States Agency for International Development (USAID) under the terms of cooperative agreement no. AIDOAA-A-17-00018. The contents of this document are the sole responsibility of Breakthrough RESEARCH and Population Council and do not necessarily reflect the views of USAID or the United States Government.

\section{POPULATION} COUNCIL

Ideas. Evidence. Impact.

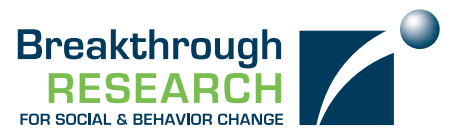

Breakthrough RESEARCH catalyzes social and behavior change (SBC) by conducting state-ofthe-art research and evaluation and promoting evidence-based solutions to improve health and development programs around the world. Breakthrough RESEARCH is a consortium led by the Population Council in partnership with Avenir Health, ideas42, Institute for Reproductive Health at Georgetown University, Population Reference Bureau, and Tulane University. 